REVISTA DO CENTRO DE CIÊNCIAS DA EDUCAÇÃO

Volume 38, n. 4 - p. 01-06, out./dez. 2020 - Florianópolis

\title{
A produção e reprodução do conhecimento em contextos adversos: um ano que não esqueceremos
}

Estamos finalizando o ano de 2020, em um contexto que, lamentavelmente, não podemos augurar melhorias, já que os contágios e as mortes alcançam, no Brasil e no mundo, cifras cada vez maiores. Mesmo assim, e com o mais profundo respeito pela vida, como uma questão de prioridade ontológica, finalizamos o quarto e último número do volume 38 da Revista Perspectiva. Isto significa que os desafios elencados no Editorial do número anterior, sobre o Ensino Remoto e as condições de trabalho dos profissionais da educação ainda são temas que não podem ser ignorados nem considerados en passant, pois se mantém presentes (embora corpos ausentes) no dia a dia nas instituições educacionais e, no caso particular, das universidades. Esta presença implica que problemas educacionais continuam e se agudizaram, se manifestando em declarações, decretos e cortes de recursos que colocam a Educação em patamares de riscos cada vez mais graves, pois o desmonte da educação laica, pública e socialmente referenciada passa por decisões unívocas, com pouca participação da comunidade acadêmica. Esta veemência de decisões chega a todos os níveis educacionais, implicando uma perda de qualidade nos processos de ensino e aprendizagem e na reprodução e produção de conhecimento. Cabe sempre reforçar que não estamos ausentes nem fora desse contexto.

Apesar disto, consideramos que o movimento do fluxo histórico/social da materialidade do mundo objetivo está permeado pela pesquisa que busca compreender os fenômenos em sua profundidade e explicá-los e pelas reflexões necessárias advindas dessa produção que nos diz sobre o "espírito do tempo". Conhecer para favorecer o desenvolvimento das máximas capacidades humanas, um desdobramento do cognitivo, o emocional, ético e estético, em que a sensibilidade e o conhecimento do humano se tornam a prioridade nas relações sociais.

Talvez, seja por esta razão que a Perspectiva continua apostando na força do para-se e o para nós, onde muitos autores e autoras deixam suas marcas, seus traços mais eloquentes sobre o movimento da realidade. Produções acadêmicas com diferentes abordagens, como se aprecia naquilo que se diz "universalidade", para que cada leitor e leitora, tome em suas mãos, segundo suas convicções, aquilo que lhe permite avançar e continuar com os estudos e com as atividades teórico-práticas na sua profissão e na vida. 
Agradecemos a confiança de todos e todas que passaram e ficaram "impressos" nas páginas destes quatros volumes, lembrando que sempre ficarão páginas em branco, com futuros desafios, e com leitores e leitoras que poderão, no caso, preencher esse silêncio por detrás das palavras não ditas.

Compõem esse número o Dossiê Migração e Educação organizado por Célia Regina Vendramini, professora do Departamento em Estudos Especiais de Educação (EED), do Centro de Ciências da Educação (CED), da Universidade Federal de Santa Catarina (UFSC). Os artigos do Dossiê são resultado de pesquisas sobre as migrações que têm um forte impacto social em uma quantidade expressiva de trabalhadores e trabalhadoras, revelando questões urgentes para serem debatidas. Também, expressam e nos instigam a apreender como os processos educacionais atendem, pensam e incorporam estas vidas de pessoas que precisaram migrar de seus lugares, mudar de hábitos e identificações, em um sistema de sociabilidade do capital que intensifica ainda muito mais as desigualdades nesta população em trânsito e permanências provisórias.

Além do Dossiê, acompanham este volume dezesseis (16) artigos de demanda continua que enriquecem a leitura com diversos temas e abordagem que, o leitor e a leitora, poderão usufruir e se deleitar, a partir de alternativas para suas escolhas.

No primeiro artigo, A Consciência do EU e a Psicologia de Steiner e Wallon, Jonas Bach Junior e Elizabete Villibor Flory abordam o desenvolvimento da consciência do eu e apresentam um estudo comparativo entre Rudolf Steiner e Henri Wallon, em relação "ao surgimento na criança da autoconsciência da personalidade por volta dos três anos", destacando que inserem os dois autores na "perspectiva contemporânea da psicologia da educação".

O segundo artigo, Intervenção Pedagógica e Mediação: convergências entre Teoria Histórico-Cultural e Yves Lenoir, é de autoria de Larissa Gotti Pissinatti e Nerli Nonato Ribeiro Mori. As autoras analisam a relação do conceito "intervenção pedagógica", proposta pelo autor Yves Lenoir, e o conceito de mediação proposto pela Teoria Histórico-cultural. A partir de uma abordagem histórica do termo intervenção e do estudo dos pressupostos da Teoria Histórico-cultural, com suporte em Lev Semenovich Vigotski, identificam aspectos de convergências entre as duas categorias, em especial, a identificação de elementos que permitem relacionar os termos: desejo, práxis e interdisciplinaridade.

No artigo As parcerias público-privadas em educação e as redes de políticas: um estudo sobre uma consultoria em gestão escolar, as autoras Maria Fátima Cóssio, Susana Schneid Scherer e Daniela Oliveira Lopes analisam os resultados da parceria público/privado a partir da contratação, por parte da Prefeitura municipal de Pelotas, Estado do Rio Grande do Sul, Brasil, de uma empresa de Consultoria para assessorar a gestão das escolas $\mathrm{O}$ objetivo da pesquisa foi o de "analisar os possíveis impactos dessa consultoria na gestão das escolas na rede". 
O artigo, Sujeitos/as da Educação de Jovens e Adultos/as: múltiplos aspectos da diversidade etária na composição de turmas no/do município de Itajaí-SC, autoria de Samanta de Borba Pinto e Eliane Juraski Camillo, objetiva reconhecer e descrever a diversidade na composição de turmas de Educação de Jovens e Adultos/as da rede de educação municipal em Itajaí/SC, Brasil. A partir da análise dos dados estatísticos sobre a composição da EJA e a observação dos próprios/as sujeitos envolvidos no processo educacional, permitiu compreender, levando em conta os saberes singulares do fazer educativo, a legitimação das vivências e experiências singulares de um/uma e outros/as de forma solidária.

Jeferson Luis da Silva, Cleber Gibbon Ratto e Elmer Erico Link, no texto Cotidiano escolar e justificação científica do fazer pedagógico: contradições, distanciamentos e perspectivas de luta no campo da formação humana, apresentam um ensaio teórico em relação a "alta produção de conhecimento das ciências humanas em educação e a constatação de uma crescente perda de qualidade da educação básica no país". A reflexão teórica dos autores questiona um distanciamento da prática educativa em relação ao projeto de humanização e civilizatório frente as atuais demandas econômicas e falta de recursos e de oportunidades de autorrealização social.

O artigo "Levados da Breca": a medicalização infantil no âmbito escolar, de autoria de George Saliba Manske e Daniela Cristina Rático de Quadros, traz um tema bastante instigante sobre os processos culturais e sua incidência nos "corpos infantes nos mais variados espaços onde estão inseridos". Entendendo a infância como uma "invenção moderna" e partindo de uma concepção histórica, o texto apresenta uma pesquisa realizada em um município no Sul de Brasil, com o intuito de compreender os processos de encaminhamento de crianças aos especialistas na área de saúde, responsáveis pelos diagnósticos e tratamentos biomédicos de transtornos relacionados à infância. O texto convida os leitores/as a repensar "como práticas de medicalização se disseminam dentro e fora das escolas e que efeitos geram na construção de sujeitos e comunidades".

O texto Formação de professores da Educação de Jovens e Adultos no âmbito das mídias digitais, de autoria de Rosemary Lapa de Oliveira, Valter Manoel da Silva Junior, Ana Paula Silva da Conceição e Cássia Cilene de Almeida Chalá Machado, discute as mídias digitais na formação docente para a Educação de Jovens e Adultos (EJA). Com o intuito de analisar a interação do uso das tecnologias da informação e comunicação na formação continuada dos/as professores/as, os autores optaram pela pesquisa-ação e realização de oficinas com professionais da EJA. Levando em conta os saberes da formação inicial e o planejamento de ensino na língua materna na EJA, a pesquisa indica que o letramento digital, se constitui como uma das interfaces pedagógicas de construção de saberes para a utilização das tecnologias.

A importância da literatura na constituição do sujeito é destacada no artigo Para além do céu, da terra e do mar: caminhos possíveis para a leitura literária 
na escola, de Vanderleia Schons, Lovani Volmer e Rosemari Martins. No presente texto se analisa um projeto de leitura como "possibilidade efetiva de prática docente com leitura literária na escola" e como um espaço de cognição, criação e fruição. Em termos metodológicos, a pesquisa-intervenção utiliza o método cartográfico, que prioriza os interesses e o perfil dos/das estudantes; assim, as leituras de narrativas literárias, as escolhas dos caminhos a seguir pelos/as alunos/as, estão de acordo com as experiencias de cada um/a, o que possibilita uma formação humanizadora em relação à literatura.

Os autores Maicon Dorigatti, Cláudia Soave e Geraldo Antonio da Rosa apresentam no artigo Possíveis reverberações para emancipação e representação cultural Latino-Americana: (des)compassos a partir de perspectivas decoloniais algumas reflexões e práticas que se desenvolvem em América Latina, a partir de uma perspectiva decolonial e de uma pedagogia crítica. O texto nos desafia a pensar as influências das políticas "emanadas dos sistemas neoliberal-capitalista e centrais" que incidem fortemente no cultural. Desta maneira, e como manifestam os autores, este artigo objetiva refletir "sobre possíveis formas de descolonizar o pensamento, amparado por um olhar sobre as produções culturais latino-americanas, que fortalecem a representatividade dos contextos locais".

Entendendo que existem diferentes concepções e prática pedagógicas na Educação Hospitalar, Roger Trindade Pereira e Carmem Lucia Artioli Rolim em seu artigo Compreensões sobre as perspectivas pedagógicas desenvolvidas no atendimento educacional hospitalar e domiciliar no Brasil, buscam identificar estas diferentes concepções. Para tal fim, realizam uma pesquisa bibliográfica que abarca o período de 2014 a 2017. A partir da análise de conteúdo das informações e dos dados coletados, os autores identificaram três categorias temáticas: LúdicoTerapêutica; Pedagógico-Educacional; e Confluência Lúdico-Educacional, que permitiram desenvolver dimensões analíticas cujos resultados mostram interessantes elementos de compreensão das diferentes perspectivas. Estas contribuem, segundo os autores, para a configuração de uma "matriz de referência teórico-conceitual, mediante exame das fontes disponíveis, servindo de base para estudos sobre o tema".

No décimo primeiro artigo desta seção de demanda contínua, Paulo Vaz de Carvalho e Cássia Geciauskas Sofiato, nos apresentam o artigo Materiais lexicográficos e pedagógicos para a educação de surdos: revisitando a história e as produções. Os autores têm como objetivo inventariar os "materiais lexicográficos e pedagógicos portugueses e brasileiros para a educação de surdos e refletir sobre suas concepções didático-pedagógicas a partir do século XVIII", com base em uma pesquisa qualitativa de tipo bibliográfica e documental. Ao final do presente estudo, os autores indicam que existe uma considerável quantidade de materiais lexicográficos e pedagógicos produzidos de diferentes formas.

O método de Marx. Em busca de sua apreensão, de Paulo Sergio Tumolo, como bem assinala o autor, tem o intuito de analisar o método de Marx, "com base 
em seus principais textos, para, em seguida, estabelecer um diálogo crítico com o método de ensino da Pedagogia Histórico-Crítica e finalizar com algumas considerações sobre o significado político do método marxiano". Paulo Sergio Tumolo realiza uma instigante consideração, a de que seria possível encontrar dois métodos, mas os leitores/as poderão observar que, no percurso de seu texto, explicará que, na verdade, é “apenas um, que é o método de Marx, uma vez que o método da crítica da economia política é o método de apreensão da base material da forma social do capital, e, por isso, parte inseparável daquele”.

O décimo terceiro artigo denominado A ruptura com a categoria de totalidade e suas principais implicações para a pesquisa em educação, de Magda Gisela Cruz dos Santos, Paulo Eduardo Dias Taddei e Vanessa Gonçalves Dias, desenvolve criticamente a ruptura realizada em relação à categoria totalidade, central no Materialismo Histórico Dialético. Para tal fim, realiza um percurso crítico da chamada "agenda pós-moderna" sustentada em um relativismo ontológico e um ceticismo epistemológico, mostrando, assim, as implicações desta no campo do conhecimento científico.

$O$ artigo Violência sexual contra crianças e adolescentes: a escola como canal de proteção e denúncia, de Marcio de Oliveira, Fernando Guimarães Oliveira da Silva e Eliane Rose Maio, aborda um tema muito importante ao se pensar nas crianças e adolescentes. Nesse sentido, os autores debatem o papel das instituições escolares e a proteção que eles/as recebem "contra experiências de violência sexual, além de enfatizar que é um canal significativo para a denúncia”. O estudo se apoia nos Estudos de Gênero e nos Estudos Feministas, permeados nos debates sobre a Educação em Direitos Humanos. Esta pesquisa documental e bibliográfica, observou que os professores/as reconhecem o seu compromisso social com a denúncia, mas que se requer maior preparação e um trabalho de equipe nas unidades escolares.

Rafael Nagy Ramos e Carla Busato Zandavalli M. Araujo nos apresentam o artigo As influências do PIBID sobre a formação inicial e a prática docente na Educação Básica, nos cursos de licenciatura presenciais na Universidade Federal de Mato Grosso do Sul. O objetivo do texto, como assinalam seus autores, é o de analisar a influência do PIBID sobre a formação inicial e a prática docente na Educação Básica, tendo como recorte os Cursos das Licenciaturas presenciais na Universidade Federal de Mato Grosso do Sul no Brasil, entre 2009 e 2018 . O estudo foi realizado em três etapas, identificando algumas categorias em relação ao Programa, qual sejam: "relação teoria-prática; formação; oportunidade; conhecimento; importância; inovação e identidade profissional". Os autores identificam um maior fluxo de informações entre as instituições de ensino superior (IES e a escola), como, também, uma maior formação de identidade profissional docente e crescimento acadêmico.

No Decimo sexto artigo deste volume, Modos de habitar a profissão docente na Educação Básica: estado da arte das pesquisas na Bahia, Jane Adriana 


\section{Editores Científicos}

David Antonio da Costa

Diana Carvalho de Carvalho

Eliane Santana Dias Debus

Juliana Cristina Faggion Bergmann

Patricia Laura Torriglia
Vasconcelos Pacheco Rios apresenta um estado da arte sobre a profissão docente no Estado da Bahia, Brasil, durante os anos 2008 e 2017. Interessou à autora identificar as principais temáticas sobre o tema, as tendencias da produção e as abordagens teórico-metodológicas nas universidades públicas da Bahia. Os resultados indicam uma prevalência em relação à formação docente, pesquisas autobiográficas que utilizam estudos de casos, Etnometodologia e pesquisas aplicadas, sendo identificada uma ausência de estudos sobre a diversidade na produção sobre a profissão docente.

Desejamos uma boa leitura a todos e todas e um necessário e ótimo ano 2021!! 